\title{
Experiences and Psychological Adjustments of Nurses Who Voluntarily Supported COVID-19 Patients in Hubei Province, China
}

This article was published in the following Dove Press journal: Psychology Research and Behavior Management

\author{
Shasha Cui ${ }^{1, *}$ \\ Lei Zhang ${ }^{2, *}$ \\ Hongyan Yan $^{3, *}$ \\ Qianyu Shi' \\ Yujun Jiang ${ }^{4}$ \\ Qin Wang ${ }^{\prime}$ \\ Jing $\mathrm{Chu}^{2}$
}

'Department of Nursing, Nantong Health College of Jiangsu Province, Nantong City, Jiangsu Province, People's Republic of China; ${ }^{2}$ Department of Nursing, Navy Medical University, Shanghai, People's Republic of China; ${ }^{3}$ Department of Neurosurgery, The Second Affiliated Hospital of Nantong University, Nantong City, Jiangsu Province, People's Republic of China; ${ }^{4}$ Department of Gynecology, The Affiliated Hospital of Qingdao University, Qingdao City, Shandong Province, People's Republic of China

*These authors contributed equally to this work
Background: The COVID-19 pandemic poses a major threat to global public health and economic development. Moreover, it has put considerable psychological pressure on nurses, who have played a vital role in the prevention and control of the epidemic.

Objective: This qualitative study aimed at exploring the experiences and psychological adjustments of nurses who voluntarily traveled to Hubei Province in China to provide support during the COVID-19 epidemic.

Methods: We conducted semi-structured, face-to-face interviews with twelve nurses recruited from three hospitals in Jiangsu Province and performed qualitative content analysis of the interview data.

Results: The following themes emerged from the analysis: (1) motivations for supporting the hardest-hit areas (professional commitment, family support, and media propaganda); (2) challenges faced during the support missions (heavy workloads, changes in working patterns, communication barriers, and barriers associated with wearing personal protective equipment); (3) psychological experiences (a sense of uncertainty, fear of infection, loneliness, stressful events, and sleep disorders); (4) psychological adjustments (adequate training and personal protective equipment, positive responses to stress, and social support); and (5) personal and professional growth (a strong professional identity, a positive work attitude, a perception of expanded possibilities, realization of the value of learning, and cherishing life). Conclusions and Recommendations: Policy makers and nursing managers should implement effective measures for supporting nurses. They include ensuring adequate workforce preparedness for nurses, strengthening protection training, including professional psychologists in support teams, encouraging nurses to apply self-regulation methods, such as exercising and listening to music, and seeking social support to promote mental health.

Keywords: coronavirus, nurse, psychological health, mental health, qualitative study

\section{Introduction}

Commencing in December 2019, an initial outbreak of Coronavirus Disease 2019 (COVID-19) rapidly spread across the globe. The COVID-19 pandemic poses a tremendous challenge to global healthcare systems. As of October 28, 2020, there were nearly 43,540,739 confirmed COVID-19 cases worldwide, including 1,160,650 deaths, reported by the World Health Organization. ${ }^{1}$ Hubei Province was hardest hit within China. Medical personnel from all over the country responded to the shortage of medical staff in this province by supporting efforts to prevent and control the epidemic. On March 1, 42,322 medical workers from
Navy Medical University, 800 Xiang Yin

Road, Shanghai 200433, People's Republic of China

Tel +86-2I-8I87 I483

Email chujing1999@smmu.edu.cn

Qin Wang

Nantong Health College of Jiangsu Province, 288 Zhen Xing Dong Road,

Nantong City, Jiangsu Province, People's

Republic of China

Email 409778029@qq.com 
across the country, including 28,679 nurses, converged in Hubei Province to combat the COVID-19 pandemic. $^{2}$ Despite being exposed to high risks of infection, frontline medical staff fully demonstrated their occupational commitment and responsibility during the epidemic. Of the confirmed COVID-19 cases globally, healthcare workers accounted for $6 \%(90,000) .{ }^{3}$ By February 11, 2020, 1716 Chinese medical workers had been infected with COVID-19, six of whom died. ${ }^{4}$

In general, healthcare workers in close contact with diagnosed patients experience higher levels of anxiety and depression ${ }^{5}$ and poorer sleep quality. ${ }^{6}$ Frontline medical staff also experience a range of somatic symptoms, such as palpitations, nausea, dyspnea, and dizziness. ${ }^{7}$ Nurses, who are professionally obliged to participate in all kinds of disaster relief work, including tackling epidemics, are prone to such symptoms. During the COVID19 pandemic, a considerable number of nurses with no previous professional experience in handling pandemics were concerned about work-related risks posed to themselves and their families. ${ }^{8}$

The levels and prevalence of anxiety induced by various professional challenges were reportedly highest among nurses relative to other healthcare workers during the pandemic. ${ }^{9,10}$ Higher working requirements and heavier workloads could affect nurses' working performance, mental health, and even threaten their lives. ${ }^{11}$ According to the results of a survey conducted in the Philippines, $37.8 \%$ of nurses exhibited dysfunctional levels of anxiety during the pandemic, which could be allayed by their personal resilience and by organizational and social support. ${ }^{3}$ Moreover, nurses spend a lot of time in isolation wards caring for patients with confirmed COVID-19 infections, thus increasing their own risks of infection. In certain countries, the risk of death may even be higher for nurses than for physicians. ${ }^{12}$ Their work in isolation wards also increases the likelihood of being witness to the suffering and death of COVID-19 patients, which could exacerbate their anxiety and fears. ${ }^{13}$ In some countries, frontline nurses reportedly lacked sufficient protective equipment while providing medical services to COVID-19 patients, causing deep distress and mental and emotional disorders. ${ }^{14}$ The quality of the medical services provided by nurses experiencing rising panic induced by the pandemic is likely to decline, along with job satisfaction, leading to a higher turnover rate. ${ }^{3}$

Since the onset of the pandemic, a growing body of research has explored how COVID-19 affects the psychological states of nurses and other medical staff. However, few of these studies have focused on the experiences, psychological changes, and adjustments of nurses who voluntarily supported COVID-19 patients in Hubei Province, which was the epicenter of the disease in China. This study provides insights for nursing administrators that can facilitate the formulation of effective interventions for safeguarding the psychological health of frontline nurses so as to maintain a strong and effective workforce.

\section{Methods}

\section{Study Design and Participants}

We developed a qualitative and descriptive methodology for this study. The participants were nurses who had volunteered to work in Hubei Province during the COVID-19 pandemic. We used a purposive sampling method, which enables the collection of useful data based on the identification of individuals possessing sufficient information, to recruit participants from three hospitals in Jiangsu Province. We used the following inclusion criteria to select participants: (1) they were registered nurses, (2) they were involved in efforts to combat COVID-19 in Hubei Province, and (3) they volunteered to share their experiences and thoughts. A total of twelve nurses participated in this study. Table 1 presents their demographic profiles.

\section{Data Collection}

In line with the aims of the study, we formulated a structured interview checklist comprising the following openended questions. (1) Why did you volunteer to support COVID-19 patients in Hubei Province? (2) What memorable events occurred during the support mission? How did you feel about them? (3) Did you encounter any difficulties in your work in Hubei province? If so, how did you overcome these difficulties? (4) After the mission ended, were there any changes in your life? The interviews were conducted between April 10 and May 7, 2020, mostly in the hospital ward meeting rooms. Each interview lasted 30-50 minutes.

\section{Data Analysis}

All of the interviews were audiotaped and transcribed verbatim. We used the NVivo 11.0 software package to perform a qualitative content analysis of the interview data. Our interpretations were validated by all of the participants, thus ensuring their credibility. 
Table I Participants' Demographic Characteristics ( $\mathrm{N}=12)$

\begin{tabular}{|c|c|c|c|}
\hline Demographics & Mean (SD) & Range & n (\%) \\
\hline Age (years) & $34.67 \pm 4.10$ & $\begin{array}{l}25-30 \\
3 I-35 \\
36-40 \\
4 I-45\end{array}$ & $\begin{array}{l}2(16.67 \%) \\
5(41.67 \%) \\
4(33.33 \%) \\
I(8.33 \%)\end{array}$ \\
\hline Sex & & $\begin{array}{l}\text { Female } \\
\text { Male }\end{array}$ & $\begin{array}{l}12(100 \%) \\
0(0 \%)\end{array}$ \\
\hline Designation & & $\begin{array}{l}\text { Nurse practitioner } \\
\text { Nurse-in-charge } \\
\text { Co-chief superintendent nurse }\end{array}$ & $\begin{array}{l}4(33.33 \%) \\
6(50 \%) \\
2(16.67 \%)\end{array}$ \\
\hline Working experience (years) & $13.58 \pm 4.66$ & $\begin{array}{l}6-10 \\
11-15 \\
16-20 \\
21-25\end{array}$ & $\begin{array}{l}4(33.33 \%) \\
4(33.33 \%) \\
3(25 \%) \\
I(8.33 \%)\end{array}$ \\
\hline Marital status & & $\begin{array}{l}\text { Married } \\
\text { Divorced }\end{array}$ & $\begin{array}{l}\text { II (9I.67\%) } \\
\text { I (8.33\%) }\end{array}$ \\
\hline Having children & & $\begin{array}{l}\text { Yes } \\
\text { No }\end{array}$ & $\begin{array}{l}12(100 \%) \\
0(0 \%)\end{array}$ \\
\hline City where support was provided & & $\begin{array}{l}\text { Wuhan } \\
\text { Huangshi }\end{array}$ & $\begin{array}{l}3(25 \%) \\
9(75 \%)\end{array}$ \\
\hline Duration of support (days) & $4|.83 \pm| 1.4 \mid$ & $\begin{array}{l}26-35 \\
36-45 \\
46-55 \\
\geq 56\end{array}$ & $\begin{array}{l}4(33.33 \%) \\
\text { I (8.33\%) } \\
6(50 \%) \\
\text { I (8.33\%) }\end{array}$ \\
\hline
\end{tabular}

\section{Ethical Statement}

The present study was approved by the Committee on Ethics of Medical Research at the Navy Medical University (HJEC number: 2020-LW-001) and was conducted in accordance with the principles of the Helsinki Declaration. Before initiating the interview process, our team leader contacted the heads of the three hospitals to elicit their support after explaining the purpose of the study and the selection criteria for recruiting participants. After obtaining participants' approval, we requested the participants to provide written informed consent on the days of the interviews. We have excluded any identifiable characteristics of the participants in this paper and have used code names like N1 and N2 to protect their privacy and anonymity. The participants consented to the publication of anonymized responses.

\section{Results}

The key findings of this study can be categorized under five themes: (1) motivations for supporting the hardest-hit areas, (2) challenges faced during the support missions, (3) psychological experiences, (4) psychological adjustments, and (5) personal and professional growth. Table 2 presents illustrative quotes for each theme and subtheme.

\section{Theme I: Motivations for Supporting the Hardest-Hit Areas}

The massive outbreak of COVID-19 in Hubei Province overwhelmed the provincial healthcare system. Responding to a serious shortage of medical staff, medical personnel in other provinces, including many nurses, volunteered to go to the frontlines. Four participants reported that their sense of responsibility as nurses prompted their decision to contribute to efforts to control the pandemic. Nurses, especially those with experience working in respiratory and infectious disease wards, were confident that they were adequately qualified to care for COVID-19 patients.

Given strong family-oriented values in China, family support was an important factor influencing nurses' 
Table 2 Themes and Sub-Themes Emerging from the Interviews

\begin{tabular}{|c|c|c|}
\hline Themes & Subthemes & Quotations \\
\hline \multirow[t]{3}{*}{$\begin{array}{l}\text { Motivations for supporting } \\
\text { the hardest-hit areas }\end{array}$} & $\begin{array}{l}\text { Professional } \\
\text { commitment }\end{array}$ & $\begin{array}{l}\text { I am a nurse, [and] nurses were needed there [Hubei Province]. There was not much to } \\
\text { think about. It was my passion for my profession, and a sense of responsibility. ... I } \\
\text { really wanted to go. I hoped I could do something to help others, so I signed up. (NI) }\end{array}$ \\
\hline & Family support & $\begin{array}{l}\text { Being my family members, they didn't want me to go to such a dangerous place. Later, I } \\
\text { talked with my family, telling them that I would do a good job in protecting myself. They } \\
\text { also knew that I really wanted to support Hubei Province. After we had talked, they } \\
\text { said that if I was determined to go, they would not object. (NI0) }\end{array}$ \\
\hline & Media propaganda & $\begin{array}{l}\text { At that time, I had read some media reports and learned about the situation regarding } \\
\text { medical staff and patients in Hubei Province. I just wanted to help them. I thought that if } \\
\text { I could go, I might be able to relieve the pressure on them. (NI0) }\end{array}$ \\
\hline \multirow[t]{4}{*}{$\begin{array}{l}\text { Challenges faced } \\
\text { during the support missions }\end{array}$} & Heavy workloads & $\begin{array}{l}\text { We were responsible for all of the patients' basic everyday care. The workload in this } \\
\text { area was still relatively heavy. ...There was one patient who had diarrhea four times, } \\
\text { and it was difficult for one nurse to clean up, so you had to call a partner to help you. } \\
\text { (N3) }\end{array}$ \\
\hline & $\begin{array}{l}\text { Changes in working } \\
\text { patterns }\end{array}$ & $\begin{array}{l}\text { We were not familiar with the environment, including the placement of objects, and } \\
\text { some instruments were different from ours. That could be a challenge. (N2) } \\
\text { The local isolation ward was actually a transformed normal ward, and the preparation } \\
\text { of first aid supplies was not on par with that in my previous department (ICU). (NI2) }\end{array}$ \\
\hline & Communication barriers & $\begin{array}{l}\text { In Hubei Province, only the young people could communicate with us in Mandarin. } \\
\text { Other people, especially the elderly, had major problems communicating. (NII) } \\
\text { Our faces were hardly recognizable under surgical masks and goggles. So many patients } \\
\text { did not know us at all. }(\mathrm{NI}) \\
\text { Because we wore two-layered masks, the patients could not hear us clearly, so we had } \\
\text { to repeat things more loudly. }(\mathrm{NI} 2)\end{array}$ \\
\hline & $\begin{array}{l}\text { Barriers associated with } \\
\text { wearing PPE }\end{array}$ & $\begin{array}{l}\text { As soon as I put on the PPE, I felt very hot. Then I went into the ward and walked } \\
\text { around, and in about I } 0 \text { minutes, I was sweating, finding it hard to breathe, dizzy, and } \\
\text { wanting to go outside. My clothes were soaked through within about two hours. (NI0) } \\
\text { Because of having to wear three layers of sterile gloves, my fingers were numb. When I } \\
\text { administered venipuncture and deep vein catheterization to a patient, I couldn't feel the } \\
\text { patient's blood vessels with my fingers. In addition, the goggles made it difficult for me } \\
\text { to see the patient's blood vessels, which is tantamount to saying that they were pierced } \\
\text { blindly. (N6) } \\
\text { Having to wear a mask for so long, my face was worn and blistered at that time, and the } \\
\text { skin was broken. (N4) }\end{array}$ \\
\hline \multirow[t]{2}{*}{ Psychological experiences } & Uncertainty & $\begin{array}{l}\text { We only knew that we were going to Huangshi, we did not know to which specific } \\
\text { hospital. Actually, we did not understand what lay ahead. Uncertainty made us } \\
\text { psychologically uneasy. (NI) }\end{array}$ \\
\hline & Fear of infection & $\begin{array}{l}\text { Really, I was scared. At first, I even thought there were viruses in the air in Wuhan. (N4) } \\
\text { I made a mistake in taking off the PPE. Then, I kept searching the Internet for [advice } \\
\text { on] this problem. ... Anyway, [I thought] I'd better take some medicine to prevent it, } \\
\text { and that at least gave me some psychological comfort. I took oseltamivir for } 10 \text { days. } \\
\text { (N3) } \\
\text { Two days later, the head nurse who greeted us on the first day when we entered the } \\
\text { hospital was also diagnosed with COVID-19, which was actually quite frightening. (N4) }\end{array}$ \\
\hline
\end{tabular}

(Continued) 
Table 2 (Continued).

\begin{tabular}{|c|c|c|}
\hline Themes & Subthemes & Quotations \\
\hline & Loneliness & $\begin{array}{l}\text { After work, we could only go to the canteen to pack a meal and then went back to our } \\
\text { rooms to eat it. Colleagues were not allowed to get together for dinner. Coupled with } \\
\text { the fact that we left our hometown for a completely strange place, this obviously made } \\
\text { me feel lonely. (NI) }\end{array}$ \\
\hline & Stressful events & $\begin{array}{l}\text { There was a patient who was in his eighties. After his death, when I was sorting out his } \\
\text { belongings, I saw his written will and the password written on the bank card. And then I } \\
\text { broke down, tears running down my cheeks and neck. (N5) }\end{array}$ \\
\hline & Sleep disorders & $\begin{array}{l}\text { Each time the phone rang, I would involuntarily go through the information, and then I } \\
\text { couldn't sleep. (N6) } \\
\text { Sometimes I hated the night. ...Because I'm afraid of being alone in my room, I slept } \\
\text { with the light on every day. (N8) } \\
\text { Some night shifts required us to get up at } 9 \text { p.m., which was quite different from my } \\
\text { usual schedule. So if I was on this shift, I couldn't sleep all night. (NII) }\end{array}$ \\
\hline \multirow[t]{4}{*}{ Psychological adjustments } & $\begin{array}{l}\text { Adequate training and } \\
\text { PPE can ease anxiety }\end{array}$ & $\begin{array}{l}\text { We had been trained before we entered the isolation ward, and then a few of us got } \\
\text { together and practiced wearing and removing the PPE over and over again. Later, when } \\
\text { I went to the ward, I was not so nervous and scared. (N4) }\end{array}$ \\
\hline & $\begin{array}{l}\text { Professional instinct } \\
\text { triumphs over fear }\end{array}$ & $\begin{array}{l}\text { When we came into contact with patients, at least in my case, I didn't have much fear. } \\
\text { When I cared for patients, I hoped I could do something to help them recover as soon } \\
\text { as possible. Maybe it's just a professional instinct. (NI) }\end{array}$ \\
\hline & $\begin{array}{l}\text { Positive response to } \\
\text { stress }\end{array}$ & $\begin{array}{l}\text { The psychiatrist would give us psychological counseling every week, and then get us to } \\
\text { do relaxation exercises. It worked really well. (N2) } \\
\text { When we got back to the hotel, everyone had to be in their own small room, so we } \\
\text { created a small karaoke room with the singing app and began singing in it. It was also a } \\
\text { way to release stress. (N4) } \\
\text { I wrote in a diary every day, recording what I had done and what I had gained, and this } \\
\text { made me feel much more comfortable. (NI2) }\end{array}$ \\
\hline & Social support & $\begin{array}{l}\text { My family expressed concern about me every day. They worried about whether I had } \\
\text { eaten well, put on my clothes, and slept well. The concern of my family made me less } \\
\text { stressed. (N4) } \\
\text { I always felt that I was not alone; everyone [colleagues] was together, helping each } \\
\text { other....The government has given us a lot of support and it was really not easy for } \\
\text { China to control the epidemic in such a short time. (NI0) }\end{array}$ \\
\hline \multirow[t]{3}{*}{$\begin{array}{l}\text { Personal and professional } \\
\text { growth }\end{array}$} & $\begin{array}{l}\text { Stronger professional } \\
\text { identity }\end{array}$ & $\begin{array}{l}\text { Through this incident, the sense of a social identity associated with [the] nursing } \\
\text { [profession] seems to be stronger than before. (N4) } \\
\text { To be honest, I once thought about quitting my job. But after this event, I feel that my } \\
\text { professional identity has been greatly strengthened, and I have a sense of achievement. (N7) }\end{array}$ \\
\hline & Positive work attitude & $\begin{array}{l}\text { During each shift, all patients must be photographed and [their information] uploaded } \\
\text { to the WeChat group composed of colleagues, with detailed descriptions of their } \\
\text { special conditions. Anyway, I don't think we considered this a chore. We all did it from } \\
\text { our hearts and very carefully. This attitude has a great impact on me. (N3) }\end{array}$ \\
\hline & $\begin{array}{l}\text { Harmonious } \\
\text { interpersonal } \\
\text { relationships }\end{array}$ & $\begin{array}{l}\text { One patient, when we went to facilitate his functional exercise and talk to him, was very } \\
\text { willing to communicate with us and kept thanking us. (N6) } \\
\text { Our relationships changed, just like when we had seriously ill patients, they [male } \\
\text { nurses] took the initiative to take care of them. And when we were menstruating, they } \\
\text { would also help us with some of the work. (N9) }\end{array}$ \\
\hline
\end{tabular}

(Continued) 
Table 2 (Continued).

\begin{tabular}{|l|l|l|}
\hline Themes & Subthemes & Quotations \\
\hline & Expanded possibilities & $\begin{array}{l}\text { The patient was healthy when discharged because we didn't give up on him. In the } \\
\text { future, even if there is a little hope, I do not want to give up easily. (N2) } \\
\text { After completing the mission, I felt that I had matured a lot. As long as I work hard, } \\
\text { there will be a lot of successful things. (N9) }\end{array}$ \\
\hline & Live and learn & $\begin{array}{l}\text { I think I have to continue to improve myself, and I suddenly have the impulse to study as } \\
\text { a specialist nurse and a graduate student. (N6) }\end{array}$ \\
\hline & Cherish life & $\begin{array}{l}\text { What I feel more deeply is that I should cherish everything that I have now and cherish } \\
\text { the time with my family. Because we don't know when an misfortune will happen, so we } \\
\text { should cherish the time [we have] with our families. (N2) }\end{array}$ \\
\hline
\end{tabular}

decisions to join the frontlines to combat the epidemic. Five nurses reported that their relatives, when informed of their intention to go to Hubei Province, expressed strong support. The families of three participants initially refused to consent to their travel to the hardest-hit areas but ultimately respected their decision and silently supported them following extensive communication.

The media also played an important role. Three participants mentioned that they learned about the difficult conditions in Hubei Province, such as shortages of personal protective equipment (PPE) and medical staff, from news broadcasts and social media, which fuelled their determination to do what they could to help.

\section{Theme 2: Challenges Faced During the Support Missions}

Family members of patients with confirmed COVID-19 diagnoses were not allowed to visit or be with them during their hospitalization. In addition to providing therapeutic care, nurses were also responsible for administering the patients' basic everyday care, which, as noted by four participants, significantly increased their workloads.

Of the 12 participants, two nurses were from a respiratory department and the remaining nurses were from surgery and emergency departments and intensive care units (ICUs). Five nurses stated that they lacked experience in caring for patients with infectious respiratory diseases given differences in their professional experiences and the unfamiliar environments and procedures. Moreover, medical equipment and office systems varied, which further impeded their work.

In China, every city has its own dialect. Five of the participants mentioned that language differences posed a significant obstacle for nurses from different provinces, constraining the performance of their duties and the establishment of a close rapport with patients. Additionally, two participants mentioned that nurses entering the isolation ward had to wear two-layered masks and face shields at all times. These devices not only affected communication with patients but they also increased the distance and sense of strangeness for patients.

Six participants reported that the PPE induced symptoms such as breathlessness and dizziness. Seven nurses mentioned that the PPE was inconvenient, affected their movements, and reduced their work efficiency. Two participants noted that wearing masks for extended periods could even cause stress-related injuries.

\section{Theme 3: Psychological Experiences}

After deciding to join the frontline in the fight against COVID-19 in Hubei Province, the nurses faced considerable uncertainty because they did not know where they would be assigned or the specific situations they would encounter. Six of the participants observed that such uncertainty made them apprehensive.

The increasing numbers of confirmed cases and dead patients bore testimony to the severity of the epidemic. Ten participants described feeling nervous and apprehensive about the high exposure risk when they entered the isolation ward. The nurses' anxiety and fear increased when their colleagues were diagnosed with COVID-19, when there was a risk of occupational exposure, or when they experienced cold symptoms, such as a cough. These incidents led them to repeatedly emphasize the impact of the risk of exposure on their health and even to take preventive antiviral drugs.

Nurses who travelled to Hubei Province to support efforts to control the epidemic were far away from their hometowns and their relatives. Moreover, the isolation 
rules required them to stay in their own rooms after work, so they were unable to gather with colleagues, which led to considerable loneliness for some nurses.

Two of the participants stated that they witnessed the deaths of COVID-19 patients in a critical care isolation unit. The loneliness of the patients as they died without their loved ones being present took a toll on the nurses' mental health.

Seven of the participants reported varying degrees of sleep disturbance, including difficulty falling asleep and waking up and having more dreams than usual. Such sleep disorders may be related to environmental and psychological factors, changing shift schedules, and the fear of missing notifications.

\section{Theme 4: Psychological Adjustments}

Access to adequate protective materials enabled nurses to protect themselves more effectively. Before entering the isolation ward, they underwent a series of targeted training programs and were subsequently required to pass a related test. Such training was intended to help reduce the risk of infection and to relieve anxiety.

With the systematic development of various kinds of supportive work, the nurses gradually devoted themselves to their work. Eight of the 12 participants stated that they overcame their fear of COVID-19 upon coming into contact with the patients because their nursing instincts took over.

Six participants reported that they self-initiated positive measures for dealing with stress and negative emotions. For example, they exercised, listened to music, and journaled. The medical team also included professional psychologists, who organized regular psychological counseling sessions for nurses and provided psychological interventions for individuals who needed them.

Ten participants stated that they received strong support from their families, colleagues, and the government, which enabled their work to prevent and control the epidemic to progress more smoothly. At the same time, social support partially relieved the psychological pressure.

\section{Theme 5: Personal and Professional Growth}

Eight of the 12 participants believed that their experience of the pandemic greatly enhanced their awareness of the value of their careers and induced a sense of accomplishment and pride. Not only the their professional identities but also their social identity associated with the nursing profession were strengthened.

Although frontline nurses were subjected to demanding tasks and a heavy daily workload, they did not react negatively. Four of the participants reported that their colleagues worked more carefully and mindfully in this challenging environment, which subtly affected their attitudes toward their jobs in the future.

After spending an extended period with the nurses, the patients too gained a deeper understanding of the nursing profession, and closer nurse-patient relationships were forged. Similarly, as the medical staff worked together, colleagues developed closer relationships and formed genuine friendships.

The pandemic created a feeling among the nurses that something seemingly difficult could be accomplished if they persevered. Such persistence on the part of medical staff gave patients more hope about their survival, which, as one participant noted, was essential for both the medical staff and the patients.

The participants also met many colleagues with considerable expertise in Hubei Province and were exposed to new nursing knowledge and skills. Five of the 12 participants said that they were planning their future career development and hoped to advance through continuous learning.

After this outbreak, many nurses realized the meaning of life and reflected on how they would increase the value of their limited lives by cherishing the present and everything in their lives.

\section{Discussion}

COVID-19 is a highly infectious and rapidly spreading respiratory infection. However, many nurses were willing to risk their lives to help control the epidemic in Hubei Province. Professional commitment to nursing, family support, and media publicity prompted them to volunteer to fight the pandemic in the worst-hit areas. Professional commitment emerges from a psychological connection between individuals and their occupation, with individuals recognizing the value of their occupations, which they internalize and integrate into their self-identity. ${ }^{15}$ Nurses' loyalty toward their profession during the pandemic may have stemmed from their desire to fulfill their professional commitments, which is consistent with the findings of previous studies. ${ }^{16,17}$ A strong sense of professional commitment can improve work quality and job satisfaction and reduce job stress and turnover. ${ }^{18-20}$ 
For many health workers, balancing family and work is important. One study found that family members' understanding and support induced greater confidence and a sense of self-worth among nurses and could improve their career satisfaction and personal achievements and reduce burnout and depression. ${ }^{21}$ In the early stages of the COVID-19 outbreak, governments worldwide made extensive efforts to raise public awareness regarding COVID-19 prevention and interventions through daily updates posted on websites and social media platforms. Many people learned about the severity of the pandemic, and shortages of medical staff and protective materials via the media. These reports motivated nurses to volunteer to support efforts in the worst-hit areas.

The interviews revealed that the nurse volunteers who went to Hubei Province faced several obstacles while performing their work. Apart from the need to adapt to new work patterns and routines, those nurses who were not specialized in handling infectious diseases faced an additional challenge. Nurses are at the forefront of patient care and facility management at COVID-19 treatment centers. The shortage of nurses and increasing numbers of COVID19 patients resulted in heavy workloads, ${ }^{14}$ which as previous studies have confirmed, is a predictor of stress. ${ }^{22}$

The chaotic nursing environment and lack of facilities were the most pressing problems identified by nurses. ${ }^{14}$ Although wearing PPE can reduce the risk of infection, ${ }^{23}$ the participants identified some problems associated with its use, which accord with Lam's findings. ${ }^{16}$ Continuous wearing of an N95 mask can result in the formation of pressure sores on the bridge of the nose and on the face, causing pain and even skin infections. This issue can necessitate taking sick days, which can have a detrimental effect on the functioning of the healthcare system. ${ }^{24}$ Additionally, the discomfort and inconvenience caused by wearing the PPE could reduce compliance levels relating to its use among medical staff. Consequently, a "buddy system" was adopted, with supervisors using checklists to ensure that medical personnel were applying the correct procedures for putting on and taking off the PPE to reduce self-infection and cross-infection. ${ }^{25}$ The participants' emphasis on the importance of removing the PPE properly resonates with Cook's findings that PPE should be removed after use to avoid infecting the user. Increasing complexity of the PPE corresponds to a higher risk of infection during removal. ${ }^{23}$

An important theme that emerged was nurses' psychological experiences of uncertainty, fear, stress, and sleep disorders. These experiences resonate with the findings of international studies conducted on psychological problems arising among nurses caring for COVID-19 patients. ${ }^{14,26}$ Uncertainty is an inherent characteristic of the healthcare industry and an inevitable challenge faced by healthcare professionals. ${ }^{27}$ The uncertainty associated with the pandemic and the working environment were important factors affecting the nurses' psychological states. In the early stages of the COVID-19 epidemic, more than $90 \%$ of frontline nurses reported that they were not fully prepared to manage COVID-19 patients. $^{3}$

Ambiguous disease status and uncertainty regarding COVID-19 treatment and care policies compounded the pressure on nurses, affecting the quality of nursing care. ${ }^{14}$ Moreover, certain urgent first aid technical procedures performed in the absence of adequate protection, such as endotracheal intubation requiring the use of a direct laryngoscope, increase the risk of COVID-19 infection. ${ }^{28}$ The findings of a previous study confirmed that infections occurring among frontline medical staff increased the stress and anxiety of their coworkers during the COVID19 outbreak. ${ }^{14}$ However, this sense of being in a crisis state also prompted increased vigilance, with nurses being fully aware of the seriousness of the disease, and thus more attentive to the importance of taking preventive measures. ${ }^{27}$

Frontline nurses may even experience stigma as a result of being perceived as a threat to the safety of others and a "carrier of the virus." 29 Health workers are responsible for caring for patients, while having the right to protect themselves from the virus. This situation causes a dilemma, leading to psychological conflicts and increasing levels of moral distress or injury. During the COVID-19 outbreak, nurses experienced the stress of caring for patients whose health was rapidly deteriorating and providing end-of-life care. ${ }^{30} \mathrm{~A}$ shortage of protective equipment can induce anger and frustration among nurses, who feel that their health is greatly threatened at work. Unless the government and hospitals fully support nurses, this sentiment will endure, possibly leading to the resignation of some nurses. ${ }^{30}$

Many factors can influence the mental health status of nurses during the pandemic. During public health crises, effective support and coordination of efforts by the government and hospital administrators are critical factors affecting the preparedness of medical personnel and their ability to respond. ${ }^{3}$ Shortages of personnel and protective equipment are the most pressing concerns that can only be 
solved through a well-designed system. ${ }^{14,27}$ The provision of adequate training and protective equipment, both of which are required to enter the isolation ward, can ease nurses' anxiety. Medical personnel must be adequately trained and tested on their PPE usage to ensure their safety prior to being put on duty. ${ }^{23,25}$ Further fine tuning of the emergency plan to improve the abilities of medical personnel to undertake emergency responses is a key factor determining the quality of these responses and their outcomes relating to saving patients' lives. ${ }^{31}$

Nurses had several avenues of help for psychological problems that arose during the pandemic. Counselors regularly listened to their difficulties and experiences and offered assistance accordingly. ${ }^{32}$ However, there were obstacles entailed in the intervention process. Some medical personnel were unwilling to participate in team consultations, which they considered unnecessary. More significant issues for them were their families' concern, the need for uninterrupted rest, and the lack of PPE. ${ }^{30}$ Exercising, listening to music, and journaling were stress-releasing methods applied by the participants. Studies have shown that music and yoga are effective in reducing stress and that music can be especially helpful in managing stress. ${ }^{33}$

Additionally, positive social support helps to reduce anxiety and stress. Social support can improve nurses' sense of self-efficacy, ${ }^{34}$ giving them confidence in their ability to do a good job and thus improving job satisfaction and reducing job burnout. ${ }^{35}$ Healthcare workers who have extensive social networks tend to worry less about potentially stressful events and to exhibit fewer negative physiological responses to stress. Medical work requires teamwork. Peer support is a powerful force that induces a feeling in nurses that they are not alone and increases their confidence that the epidemic will be overcome. During the COVID-19 pandemic, nurses may have worked with colleagues whom they did not know, which could have made them reluctant to seek peer support for fear that they were putting pressure on their colleagues or letting the team down. A previous study proposed strategies and interventions for promoting peer support to help new medical professionals feel safe, valued, and welcome. ${ }^{30}$

Many studies have found that outbreaks of infectious diseases are associated with psychological trauma for medical workers. ${ }^{17,36}$ At the same time, the experience of coping with traumatic life events and situations may lead to personal and professional growth for some individuals. During the COVID-19 pandemic, the professional value of nursing was fully demonstrated, with society-wide recognition of nurses, whose professional identities and sense of accomplishment were consequently strengthened. This finding is consistent with that of a previous study. ${ }^{37}$

These developments led to more harmonious nursepatient relationships, with increasing trust of nurses among patients and empathy for patients among nurses that made them more attentive to patients' feelings. Consequently, nurses engaged in profound self-reflection and began to re-examine their own values. The pandemic provided them with an opportunity to discover their strengths and perseverance, which encouraged them and enhanced their self-confidence. Moreover, they realized their own shortcomings and developed a desire to improve their knowledge and skills through further study. Further, they learned to appreciate the support extended by friends, colleagues, and the wider society and developed a more positive view about the importance of life, health, and families. These findings are consistent with those of Sun. ${ }^{37}$

\section{Limitation}

The interviews were conducted after they had completed support tasks and were released from quarantine, which may have affected their ability to describe their experiences and feelings accurately.

\section{Conclusions and Recommendations}

A high degree of professional commitment, strong social support, and the media's dissemination of accurate information increased nurses' willingness to volunteer to support COVID-19 patients in Hubei Province. However, negative experiences, such as uncertainty, fear, loneliness, and sleep disorders, may have affected the mental health of nurses and reduced the quality of nursing. It is therefore essential for policy makers and nursing managers to provide for nurses' physiological needs, such as sleep and diet by ensuring the availability of sufficient numbers of nursing staff. They should be provided with adequate PPE and training to relieve their stress and anxiety. Moreover, timely information updates on the epidemic are required to reduce their uncertainty. Frontline nurses should have access to professional psychologists who can provide them with psychological support when necessary. Nurses should be encouraged to engage in self-regulating measures, such as exercising, listening to music, and seeking social support to cope better with negative events. In addition, timely recognition of nurses' personal and professional 
growth can enhance their perceptions of their professional and social value.

\section{Acknowledgments}

The authors would like to thank the participants in this study for their valuable time and data.

\section{Disclosure}

The authors report no conflicting interests in this work. The study was supported by grants from the Health Bureau of the Logistics Support Department of the Central Military Commission (grant number 20WQ010) and the Youth Fund Project of Nantong Health Commission (grant number QB2019011). The funders had no role in the design of the study; the collection, analysis, and interpretation of data; or the writing of the manuscript.

\section{References}

1. World Health Organization. WHO Coronavirus Disease (COVID-19) Dashboard. 2020. Available from: https://covid19whoint/2020. Accesed October 28, 2020.

2. National Health Commission of the People's Republic of China. Medical workers were sent to Hubei province. 2020. Available from: http://www. nhc.gov.cn/wjw/mtbd/202003/e0d5f8a773b54fc39113988dbcb19136. shtml. Accesed November 15, 2020.

3. Labrague LJ, De Los Santos JAA. COVID-19 anxiety among frontline nurses: predictive role of organisational support, personal resilience and social support. J Nurs Manag. 2020;28(7):1653-1661. doi: 10.1111 jonm. 13121

4. National Health Commission of the People's Republic of China. A transcript of the State Council press conference held on February 2020. Available from: http://www.nhc.gov.cn/xcs/fkdt/202002/ 5329d7ab7af24690a1d5b66982333af3.shtml. Accesed November $15,2020$.

5. Lu W, Wang H, Lin Y, Li L. Psychological status of medical workforce during the COVID-19 pandemic: a cross-sectional study. Psychiatry Res. 2020;288:112936. doi:10.1016/j.psychres.2020.112936

6. Xiao H, Zhang Y, Kong D, Li S, Yang N. The Effects of Social Support on Sleep Quality of Medical Staff Treating Patients with Coronavirus Disease 2019 (COVID-19) in January and February 2020 in China. Med Sci Monit. 2020;26:e923549. doi:10.12659/ MSM.923921

7. Yifan T, Ying L, Chunhong G, et al. Symptom Cluster of ICU nurses treating COVID-19 pneumonia patients in Wuhan, China. J Pain Symptom Manage. 2020;60(1):e48-e53. doi:10.1016/j.jpainsymman.2020.03.039

8. Halcomb E, McInnes S, Williams A, et al. The experiences of primary healthcare nurses during the COVID-19 Pandemic in Australia. J Nurs Scholarsh. 2020;52(5):553-563. doi:10.1111/ jnu. 12589

9. Luo M, Guo L, Yu M, Jiang W, Wang H. The psychological and mental impact of coronavirus disease 2019 (COVID-19) on medical staff and general public - a systematic review and meta-analysis. Psychiatry Res. 2020;291:113190. doi:10.1016/j.psychres.2020.11 3190

10. M Y, et al. Work stress among Chinese nurses to support Wuhan in fighting against COVID-19 epidemic. J Nurs Manage. 2020;28 (5):1002-1009. doi:10.1111/jonm.13014

11. Maben J, Bridges J. Covid-19: supporting nurses` psychological and mental health. J Clin Nurs. 2020;29(15-16):2742-2750.
12. Jackson D, Anders R, Padula WV, Daly J, Davidson PM. Vulnerability of nurse and physicians with COVID-19: monitoring and surveillance needed. J Clin Nurs. 2020. doi:10.1111/jocn.15347

13. Pappa S, Ntella V, Giannakas T, Giannakoulis VG, Papoutsi E, Katsaounou P. Prevalence of depression, anxiety, and insomnia among healthcare workers during the COVID-19 pandemic: a systematic review and meta-analysis. Brain Behav Immun. 2020;88:901907. doi:10.1016/j.bbi.2020.05.026

14. Karimi Z, Fereidouni Z, Behnammoghadam M, et al. The lived experience of nurses caring for patients with COVID-19 in Iran: a phenomenological study. Risk Manag Healthc Policy. 2020;13:12711278. doi:10.2147/RMHP.S258785

15. Lee K, Carswell JJ, Allen NJ. A meta-analytic review of occupational commitment: relations with person- and work-related variables. $J$ Appl Psychol. 2000;85(5):799-811. doi:10.1037/0021-9010.85.5.799

16. Lam KK, Hung SY. Perceptions of emergency nurses during the human swine influenza outbreak: a qualitative study. Int Emerg Nurs. 2013;21(4):240-246. doi:10.1016/j.ienj.2012.08.008

17. Khalid I, Khalid TJ, Qabajah MR, Barnard AG, Qushmaq IA. Healthcare workers emotions, perceived stressors and coping strategies during a MERS-CoV outbreak. Clin Med Res. 2016;14(1):7-14. doi:10.3121/cmr.2016.1303

18. Barac I, Prlic N, Pluzaric J, Farcic N, Kovacevic S. The mediating role of nurses' professional commitment in the relationship between core self-evaluation and job satisfaction. Int J Occup Med Environ Health. 2018;31(5):649-658.

19. Chenevert D, Jourdain G, Vandenberghe C. The role of high-involvement work practices and professional self-image in nursing recruits' turnover: a three-year prospective study. Int J Nurs Stud. 2016;53:7384. doi:10.1016/j.ijnurstu.2015.09.005

20. Teng CI, Dai YT, Shyu YI, et al. Professional commitment, patient safety, and patient-perceived care quality. J Nnurs Scholarsh. 2009;41 (3):301-309. doi:10.1111/j.1547-5069.2009.01289.x

21. Bratis D, Tselebis A, Sikaras C, et al. Alexithymia and its association with burnout, depression and family support among Greek nursing staff. Hum Resour Health. 2009;7:72. doi:10.1186/1478-4491-7-72

22. Mohammed A, Sheikh TL, Poggensee G, et al. Mental health in emergency response: lessons from Ebola. Lancet Psychiatry. 2015;2 (11):955-957. doi:10.1016/S2215-0366(15)00451-4

23. Cook TM. Personal protective equipment during the COVID-19 pandemic - a narrative review. Anaesthesia. 2020;75(7):920-927. doi:10.1111/anae.15071

24. Yin Z. Covid-19. Countermeasure for N95 mask-induced pressure sore. J Eur Acad Dermatol Venereol. 2020;34(7):e294-e295. doi:10. $1111 / \mathrm{jdv} .16490$

25. Herron JBT, Hay-David AGC, Gilliam AD, Brennan PA. Personal protective equipment and Covid 19- a risk to healthcare staff? $\mathrm{Br} J$ Oral Maxillofac Surg. 2020;58(5):500-502. doi:10.1016/j.bjoms.20 20.04.015

26. Labrague LJ, Santos JAA. Fear of COVID-19, psychological distress, work satisfaction and turnover intention among frontline nurses. $J$ Nurs Manag. 2020. doi:10.1111/jonm.13168

27. Lam SKK, Kwong EWY, Hung MSY, Pang SMC, Chien WT. A qualitative descriptive study of the contextual factors influencing the practice of emergency nurses in managing emerging infectious diseases. Int J Qual Stud Health Well-Being. 2019;14(1):1626179. doi:10.1080/17482631.2019.1626179

28. Smereka J, Szarpak L. The use of personal protective equipment in the COVID-19 pandemic era. Am J Emerg Med. 2020;38(7):15291530. doi:10.1016/j.ajem.2020.04.028

29. Rodriguez-Vega B, Amador B, Ortiz-Villalobos A, et al. The psychosocial response to the ebola health emergency: experience in Madrid, Spain. Clin Infect Dis. 2015;60(12):1866-1867. doi:10.1093/cid/ civ173

30. Maben J, Bridges J. Covid-19: supporting nurses' psychological and mental health. J Clin Nurs. 2020;29(15-16):2742-2750 
31. Tomblin Murphy G, MacKenzie A, Alder R, Langley J, Hickey M, Cook A. Pilot-testing an applied competency-based approach to health human resources planning. Health Policy Plan. 2013;28 (7):739-749. doi:10.1093/heapol/czs115

32. Chen Q, Liang M, Li Y, et al. Mental health care for medical staff in China during the COVID-19 outbreak. Lancet Psychiatry. 2020;7(4): e15-e16. doi:10.1016/S2215-0366(20)30078-X

33. Joshi A, Kiran R. Gauging the effectiveness of music and yoga for reducing stress among engineering students: an investigation based on Galvanic Skin Response. Work. 2020;65(3):671-678. doi:10.3233/ WOR-203121

34. Hu SH, Yu YM, Chang WY, Lin YK. Social support and factors associated with self-efficacy among acute-care nurse practitioners. $J$ Clin Nurs. 2018;27(3-4):876-882. doi:10.1111/jocn.14129
35. MH K, RTS H. The relationship between caring preceptor, selfefficacy, job satisfaction, and new nurse performance. Enferm Clin. 2019;29(Supplement 2):464-470.

36. Shaw SCK. Hopelessness, helplessness and resilience: the importance of safeguarding our trainees' mental wellbeing during the COVID-19 pandemic. Nurse Educ Pract. 2020;44:102780. doi:10.1016/j.nepr.2020.102780

37. Sun N, Wei L, Shi S, et al. A qualitative study on the psychological experience of caregivers of COVID-19 patients. Am J Infect Control. 2020;48(6):592-598. doi:10.1016/j.ajic.2020.03.018

\section{Publish your work in this journal}

Psychology Research and Behavior Management is an international, peer-reviewed, open access journal focusing on the science of psychology and its application in behavior management to develop improved outcomes in the clinical, educational, sports and business arenas. Specific topics covered in the journal include: Neuroscience, memory and decision making; Behavior modification and management; Clinical applications; Business and sports performance management; Social and developmental studies; Animal studies. The manuscript management system is completely online and includes a very quick and fair peer-review system, which is all easy to use. Visit http://www. dovepress.com/testimonials.php to read real quotes from published authors. 